\title{
The soil microbiomics of intact, degraded and partially- restored semi-arid succulent thicket (Albany Subtropical Thicket)
}

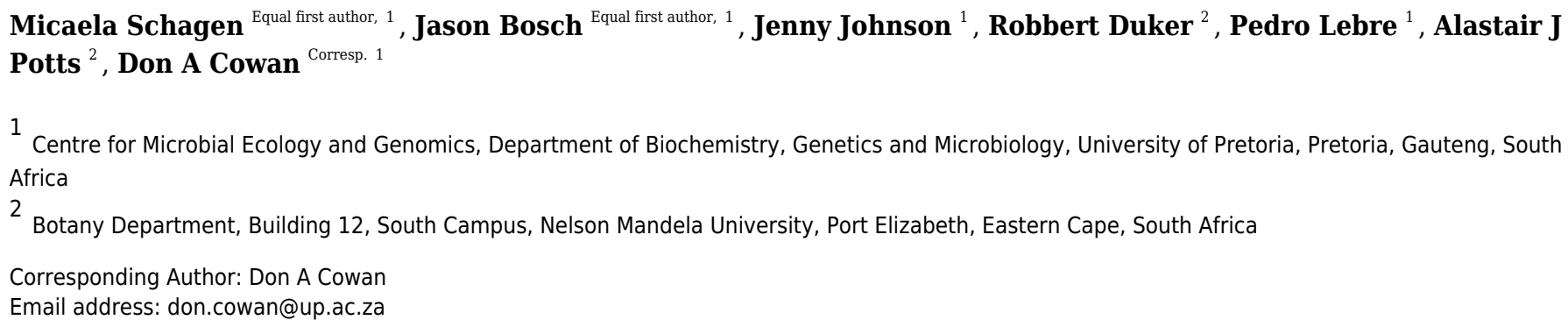

This study examines the soil bacterial diversity in the Portulacaria afra-dominated succulent thicket vegetation of the Albany Thicket biome; this biome is endemic to South Africa. The aim of the study was to compare the soil microbiomes between intact and degraded zones in the succulent thicket and identify environmental factors which could explain the community compositions. Bacterial diversity, using 16S amplicon sequencing, and soil physicochemistry were compared across three zones: intact (undisturbed and vegetated), degraded (near complete removal of vegetation due to browsing) and restored (a previously degraded area which was replanted approximately 11 years before sampling). Amplicon Sequence Variant (ASV) richness was similar across the three zones, however, the bacterial community composition and soil physicochemistry differed across the intact and degraded zones. We identified the major drivers of microbial community composition as soil density, $\mathrm{pH}$ and the ratio of $\mathrm{Ca}$ to $\mathrm{Mg}$. The restored zone was intermediate between the intact and degraded zones. The differences in the microbial communities appeared to be driven by the presence of plants, with plant-associated taxa dominating in the intact zone. The dominant taxa in the degraded zone were cosmopolitan organisms, that have been reported globally in a wide variety of habitats. This study provides baseline information on the changes of the soil bacterial community of a spatially restricted and threatened biome. It also provides a starting point for further studies on community composition and function concerning the restoration of degraded succulent thicket ecosystems 
1 The soil microbiomics of intact, degraded and

2 partially-restored semi-arid succulent thicket (Albany

3 Subtropical Thicket)

4 Micaela Schagen ${ }^{1+}$, Jason Bosch ${ }^{1+}$, Jenny Johnson ${ }^{1}$, Robbert Duker ${ }^{2}$, Pedro H. Lebre ${ }^{1}$, Alastair

5 Potts $^{2}$, Don A. Cowan ${ }^{1}$

6 1. Centre for Microbial Ecology and Genomics, Department of Biochemistry, Genetics and

$7 \quad$ Microbiology, University of Pretoria, Pretoria, Gauteng, South Africa

8 2. Botany Department, Building 12, South Campus, Nelson Mandela University, Port

$9 \quad$ Elizabeth, Eastern Cape, South Africa

$10{ }^{+}$These authors contributed equally to this work.

11 Corresponding Author:

12 Don A. Cowan

13 Centre for Microbial Ecology and Genomics, Department of Biochemistry, Genetics and

14 Microbiology, University of Pretoria, Pretoria, Gauteng, 0002, South Africa

15 Email address: don.cowan@up.ac.za 


\section{Abstract}

This study examines the soil bacterial diversity in the Portulacaria afra-dominated succulent thicket vegetation of the Albany Thicket biome; this biome is endemic to South Africa. The aim of the study was to compare the soil microbiomes between intact and degraded zones in the succulent thicket and identify environmental factors which could explain the community compositions. Bacterial diversity, using 16S amplicon sequencing, and soil physicochemistry were compared across three zones: intact (undisturbed and vegetated), degraded (near complete removal of vegetation due to browsing) and restored (a previously degraded area which was replanted approximately 11 years before sampling). Amplicon Sequence Variant (ASV) richness was similar across the three zones, however, the bacterial community composition and soil physicochemistry differed across the intact and degraded zones. We identified the major drivers of microbial community composition as soil density, $\mathrm{pH}$ and the ratio of $\mathrm{Ca}$ to $\mathrm{Mg}$. The restored zone was intermediate between the intact and degraded zones. The differences in the microbial communities appeared to be driven by the presence of plants, with plant-associated taxa dominating in the intact zone. The dominant taxa in the degraded zone were cosmopolitan organisms, that have been reported globally in a wide variety of habitats. This study provides baseline information on the changes of the soil bacterial community of a spatially restricted and threatened biome. It also provides a starting point for further studies on community composition and function concerning the restoration of degraded succulent thicket ecosystems.

\section{Introduction}

The Albany Subtropical Thicket is a biome unique to South Africa that possesses a rich floristic diversity (Hoare et al., 2006); it consists of various forms of closed canopy shrubland, less than three meters in average canopy height, that grade into forest above $\sim 800 \mathrm{~mm}$ annual precipitation and into karroid shrubland below 200 mm (Vlok, Euston-Brown \& Cowling, 2003). Here we focus on an arid thicket type (100-500 mm mean annual precipitation) where large succulent shrubs, particularly Portulacaria afra (commonly known as “spekboom”), dominate the canopy (Vlok, Euston-Brown \& Cowling, 2003). The succulent-rich thicket types have been noted for their impressive carbon storage, given the semi-arid climates in which they occur (Mills \& Cowling, 2010; van der Vyver \& Cowling, 2019). This biome predominantly occurs in the Eastern Cape region and extends into the Western Cape province, constituting 2.5\% of the land area of South Africa (Cowling et al., 2005) — the "arid" and "valley” thicket structural types, where P. afra can be abundant, comprise over $50 \%$ of the biome (Vlok, Euston-Brown \& Cowling, 2003; Dayaram et al., 2019). The Albany Subtropical Thicket is restricted to deep, welldrained, fertile, sandy loams with the densest thickets occurring in the deepest soils (Cowling, 1983; Vlok, Euston-Brown \& Cowling, 2003) and occurs in semi-arid regions where there is some degree of fire and frost protection (Duker et al., 2015b,a; Cowling \& Potts, 2015).

Portulacaria afra is considered to be an ecosystem engineer in the arid and valley thicket subtypes where it is dominant (Lechmere-Oertel, Cowling \& Kerley, 2005; Lechmere-Oertel et al., 2008; van Luijk et al., 2013). These regions are referred to as "succulent thicket" (sensu 
55 Moolman and Cowling, 1994). This stem-succulent shrub produces an unusually large biomass

56 for the arid environment in which it grows. This has been attributed to its ability to shift between

57 the C3 and crassulacean acid metabolism photosynthetic pathways (Ting \& Hanscom, 1977;

58 Guralnick \& Ting, 1987), that likely enables it to take advantage of sporadic rainfall (Mills et al.,

59 2014), store large quantities of carbon and maintain metabolic activity during drought conditions

60 by recycling organic acids (Guralnick, Rorabaugh \& Hanscom, 1984). Consequently, P. afra

61 produces copious leaf litter and root biomass, generating soils with a high soil carbon content

62 (Mills et al., 2005; Lechmere-Oertel et al., 2008; Mills \& Cowling, 2010; van der Vyver \&

63 Cowling, 2019) that enhances local soil fertility (Mills et al., 2005) and soil moisture retention

64 (van Luijk et al., 2013). In addition, the thick litter layer produced by $P$. afra improves soil

65 moisture retention (van Luijk et al., 2013) by buffering wet and dry cycles, thus creating a

66 favourable environment for other plant species (Sigwela et al., 2009; van Luijk et al., 2013;

67 Wilman et al., 2014).

68 Extensive $P$. afra removal results in an ecosystem shift similar to that found in other regions (van

69 Luijk et al., 2013) such as the Nama Karoo, open savanna or pseudo-savanna (Lechmere-Oertel,

70 Kerley \& Cowling, 2005; Mills et al., 2005). In degraded areas, soil organic carbon content is

71 substantially reduced, as is water infiltration, resulting in lower water retention and increased

72 erosion (van Luijk et al., 2013). The reduction in soil carbon content in degraded thicket habitat

73 can be attributed to diminished carbon input from leaf litter and roots (Mills \& Cowling, 2006),

74 capping, and loss of topsoil through erosion (Mills \& Fey, 2004a). It has also been suggested that

75 processes such as increased microbial activity from elevated soil temperatures (Jenkinson, 1981)

76 and increased wetting and drying cycles in exposed surface soil will increase the rate of soil

77 organic matter mineralisation (Birch, 1958). Degraded Albany Subtropical Thicket does not

78 spontaneously regenerate even in the absence of herbivory (Lechmere-Oertel, Kerley \& Cowling,

79 2005; Lechmere-Oertel, Cowling \& Kerley, 2005).

80 Approximately 60\% of the Albany Thicket biome has been severely degraded (Lloyd, Berg \&

81 Palmer, 2002) by vegetation clearing, cutting of wood and, primarily, browsing by domestic

82 herbivores. Only 11\% of the thicket's original range remains intact (Lloyd, Berg \& Palmer, 2002)

83 with the rest either transformed or moderately degraded. Attempts have been made to restore the

84 biodiversity and functionality of this ecosystem by replanting $P$. afra cuttings. These attempts

85 have met with varying degrees of success; some areas have become revegetated (Mills \&

86 Cowling, 2006; van der Vyver, Mills \& Cowling, 2021), while others have high mortality or low

87 growth rates (average 28\% survival) (Mills \& Robson, 2017). It has been suggested that soil

88 microbial diversity plays an important role in maintaining soil microbiome stability during

89 periods of stress and recovery (Garbeva et al., 2006) and this may be the case in intact Albany

90 Subtropical Thicket.

91 The relationship between terrestrial macroorganisms and microorganisms in the soil is an

92 important component in understanding the structure and function of any ecosystem.

93 Microorganisms perform important ecosystem services (Bardgett \& van der Putten, 2014),

94 including organic matter decomposition, nutrient recycling, fertility promotion and soil

95 agglomeration (Xun et al., 2018). Factors influencing soil bacterial communities include 
96 physicochemical properties, organic matter content, fertilizer treatment, land-use, water

97 availability and climate change (Brodie, Edwards \& Clipson, 2002; Marschner, 2003; Grayston et

98 al., 2004; Ulrich \& Becker, 2006; McCrackin et al., 2008; Jansson \& Hofmockel, 2020).

99 Despite the potential importance of microbial communities in the establishment and maintenance

100 of the Albany Thicket, neither the edaphic microbiomes of this region nor the impact of $P$. afra

101 removal on soil microbiome functioning has been characterised. Thus, the aim of this study is to

102 compare the compositions of the soil microbiomes between intact (vegetated) and degraded

103 succulent thicket zones and identify environmental factors that could account for observed

104 changes in the microbial community resulting from the loss of the succulent thicket vegetation.

105 Methods

\section{Sample Acquisition and soil analysis}

107 The study site, of approximately $55000 \mathrm{~m}^{2}$ (Fig. 1), was located in the Eastern Cape, South 108 Africa $\left(33.2977^{\circ} \mathrm{S}, 24.7461^{\circ} \mathrm{E}\right)$. Sampling was performed on 12 December 2019 along six 109 parallel transects with approximately $50 \mathrm{~m}$ between sample collection sites. The study site is 110 bisected by a fence where half of the land area is in a degraded state (due to over-browsing by

111 domestic animals over many decades) and half is intact (largely protected from excessive 112 browsing). Fifteen soil samples ( $0-5 \mathrm{~cm}$ depth, after removal of surface leaf litter) were 113 collected from each of the degraded and protected areas. In addition, five samples were taken 114 from under the canopy of P. afra plants that were planted in the degraded area (February 2009), 115 where a $50 \mathrm{~m}$ by $50 \mathrm{~m}$ area was fenced and a range of $P$. afra planting treatments were trialled (as 116 part of the large-scale restoration experiment detailed in Mills et al., 2015). Here we term these 117 various states of thicket vegetation as the following: the intact zone, the degraded zone, and the 118 restored zone (although the defined area was only partially restored) and a "site" is the point 119 where soil was sampled for microbial DNA extraction and soil physicochemical analysis. Soil 120 samples were stored on ice immediately after collection and transferred to a $-40{ }^{\circ} \mathrm{C}$ freezer within 121 six hours of sampling. Frozen samples were transferred from Port Elizabeth to Pretoria on ice and 122 transfer took less than eight hours. In Pretoria, the samples were stored at $-80{ }^{\circ} \mathrm{C}$ until DNA 123 extraction.

124 For each of the vegetation conditions, three iButton data loggers (DS1923-F5\# Hygrochron, 125 iButtonLink, LLC, Whitewater, USA) were placed at $5 \mathrm{~cm}$ soil depth and recorded the 126 temperature and humidity every two hours from 13 July 2020 to 6 December 2020.

127 Approximately 250 g of soil from each sample site was submitted to Intertek Agricultural

128 Services for soil chemistry analysis (Intertek, Johannesburg, South Africa). The following 129 properties were measured: soil pH (KCI), P (Bray 1/Bray 2), cations (Ca, Mg, K, Na, S) (Mehlich 130 3), exchangeable acidity, density, \%Ca, \%Mg, \%K, \%Na, Ca:Mg, Ca+Mg/K, texture (Clay, Silt, 131 Sand), total organic carbon (Walkley Black), $\mathrm{NH}_{4}-\mathrm{N}$ and $\mathrm{NO}_{3}-\mathrm{N}$. 


\section{DNA Extraction and Sequencing}

133 Metagenomic DNA (i.e. DNA found in an environmental sample) was extracted from $0.5 \mathrm{~g}$ soil

134 samples using the QIAGEN DNeasy PowerSoil kit (Qiagen, Venlo, Netherlands). The protocol

135 was modified to include an additional step of soil agitation by two 40 s cycles of $2500 \mathrm{rpm}$ in a

136 Powerlyzer 24 (Qiagen, Venlo, Netherlands). We evaluated the quantity and quality of the DNA

137 with a Nanodrop 2000 spectrophotometer (Thermo Fisher Scientific, Waltham, United States)

138 and by amplifying the bacterial 16S rRNA V3-V4 region (E9F and U1510R primers) using

139 OneTaq $^{\circledR}$ Hot Start DNA Polymerase (New England Biolabs, Ipswich, United States).

140 Metagenomic DNA was submitted to Omega Bioservices (Norcross, Georgia, United States) for

141 sequencing of the V3-V4 region of the 16S rRNA gene (Forward primer: 5'-

142 CCTACGGGNGGCWGCAG-3', reverse primer: 5'-GACTACHVGGGTATCTAATCC-3'

143 (Klindworth et al., 2013)) on an Illumina MiSeq v3 with paired-end 300 bp reads. Each sample

144 was sequenced twice.

\section{Data Analysis}

146 The raw DNA reads were processed in QIIME2 2020.8 (Bolyen et al., 2019), trimming 15 bp off

147 the start and end of the reads and denoised using DADA2 (Callahan et al., 2016) to give amplicon

148 sequence variants (ASVs) (Callahan, McMurdie \& Holmes, 2017) which identify different

149 bacterial sequences with single nucleotide accuracy. After processing, library sizes ranged from

15036067 reads to 116915 reads with a mean of 87305 reads and a median of 90359 reads. Each

151 ASV was assigned taxonomy by comparing the sequence to the SILVA 138.1 (Quast et al., 2013;

152 Yilmaz et al., 2014) database of 16S rRNA gene sequences using a naive Bayes classifier.

153 Unless otherwise stated, all data were analysed in R 4.0.3 (R Core Team, 2020) using the

154 following packages and their dependencies: Phyloseq 1.34.0 (McMurdie \& Holmes, 2013),

155 ggplot2 3.3.2 (Wickham, 2016), stringr 1.4.0 (Wickham, 2019), pheatmap 1.0.12 (Kolde, 2019),

156 RcolorBrewer 1.1-2 (Neuwirth, 2014), vegan 2.5-6 (Oksanen et al., 2019), gridExtra 2.3 (Auguie,

157 2017), NetCoMi 1.0.2.9000 (Peschel et al., 2020), lubridate 1.7.9.2 (Grolemund \& Wickham,

158 2011), ggrepel 0.9.1 (Slowikowski, 2021) and ggsignif 0.6.0 (Ahlmann-Eltze, 2019). Except for

159 alpha diversity, which was calculated on unnormalised data, all analyses used ASV data

160 transformed for relative abundance (proportions) which have the best performance for

161 community analysis (McKnight et al., 2019). Beta diversity was calculated with the quantitative

162 Jaccard metric. The Principal Co-ordinates Analysis (PCoA) used all the available ASVs but for

163 other analyses, ASVs were agglomerated at either the phylum or genus level, as specified in the

164 results where applicable. For the Principal Components Analysis (PCA) and Redundancy

165 Analysis (RDA), given that data were obtained from three iButtons per zone, we interpolated the

166 available data to generate pseudomeasurements for each site. The interpolation was performed by

167 randomly drawing each variable from a normal distribution with a mean and standard deviation

168 appropriate for each zone. In addition, the soil physicochemical values were standardised to zero

169 mean and unit variance. The appropriate model for the RDA was chosen by including the terms

170 which were selected by automatic stepwise model building using the commands ordistep and

171 ordiR2step from the R package vegan. The final model was tested and evaluated by Anova to 
172 ensure that all terms were statistically significant. The co-occurrence network was constructed

173 with associations calculated with CCREPE (also known as ReBoot) (Faust et al., 2012) and

174 called from NetCoMi with the default parameters and clustered with the default

175 "cluster_fast_greedy" algorithm (Clauset, Newman \& Moore, 2004). Linear discriminant analysis

176 Effect Size (LEfSe) (Segata et al., 2011) analysis was used to identify the bacterial taxa that were

177 differentially abundant between sites. We used the LEfSe implementation on the Huttenhower

178 Lab Galaxy Server: https://huttenhower.sph.harvard.edu/galaxy/. LEfSe uses the relative

179 abundance of the ASVs, normalised so that the ASVs counts sum to one million in each sample,

180 applies a Kruskal-Wallis test to identify features with a significant difference between the sample

181 sets and uses Linear Discriminant Analysis to estimate effect sizes; finally returning biomarkers

182 where the effect size has a logarithmic score (base 10) greater than 2 and the p-value is less than

1830.05.

184 The sample metadata are provided in the supplementary files (Table S1) and all scripts used for

185 analysis are available on Github: https://github.com/jasonbosch/The-soil-microbiomics-of-intact-

186 degraded-and-partially-restored-semi-arid-succulent-thicket

187 Results and Discussion

188 Soil physicochemistry.

189 This study is based on a detailed comparison of prokaryotic microbial diversity in the $0-5 \mathrm{~cm}$

190 soil horizon from two closely adjacent but substantially different habitats: an intact (a largely

191 undisturbed and vegetated) succulent thicket zone, and a degraded zone, where decades of

192 unsustainable browsing resulted in the near complete removal of vegetation (Fig. S1) with

193 subsequent erosion of topsoil (with bedrock evident in places). Samples taken from a partially

194 revegetated area (the restored zone) were also included to assess the impact of (partial)

195 restoration on the soil after approximately a decade of P. afra planting.

196 The two comparative areas, the intact and degraded zones, might be expected to differ in both

197 biotic and abiotic parameters due to the widely different vegetation cover of the two areas

198 (mature succulent thicket versus a sparse herbaceous layer) (Fig. 1). Specifically, the increased

199 litter inputs and shading in the undisturbed vegetated area is predicted to increase carbon input

200 and moisture retention in the soil (van Luijk et al., 2013), thereby positively impacting the soil

201 microbial communities. By comparison, degraded areas are exposed to direct sunlight and wind;

202 both of which are predicted to decrease water retention by increasing evapotranspiration and to

203 negatively impact microbial communities. However, the degraded areas may also positively

204 benefit, in highly localised patches, from the presence of domestic animals, specifically from the

205 input of urine and faeces, which might also have an impact on the microbial communities in these

206 zones (Todkill, Kerley \& Campbell, 2006).

207 Physicochemical analyses of the three primary experimental zones (intact, degraded and restored)

208 (Table S1) showed significant differences in several parameters and intact and degraded zone

209 samples clustered separately when analysed via PCA (Fig. 2A). The intact succulent thicket soil

210 samples had a significantly higher total organic carbon content than either the restored or 
211 degraded zone soils (Intact: 2.33 \pm 1.00 , Degraded: 0.72 \pm 0.28 , Restored: 1.18 \pm 0.15 ; \%; Wilcox 212 test: Intact v Degraded: $\mathrm{p}=7.71 \times 10^{-5}$, Intact v. Restored: $\mathrm{p}=2.27 \times 10^{-2}$, Degraded v. Restored: $213 \mathrm{p}=4.30 \times 10^{-3}$ ). This can be attributed to the input of leaf litter from the vegetated cover. P. afra, 214 the main component of succulent thicket vegetation, is known to create a carbon-rich soil 215 environment (Lechmere-Oertel et al., 2008; Mills \& Cowling, 2010; van der Vyver \& Cowling, 216 2019). The intact zone samples had the highest measured levels of $\mathrm{Ca}^{+}$(Intact: 3174.20 \pm 1374.18 , 217 Degraded: 2168.867 \pm 1789.83 , Restored: $1773.20 \pm 396.15 ; \mathrm{mg} / \mathrm{kg}$ ) and the lowest $\mathrm{pH}$ (Intact:

218 5.48 \pm 0.90 , Degraded: 6.84 \pm 0.75 , Restored: 6.53 \pm 0.33 ), phosphorous content (PBray1: Intact:

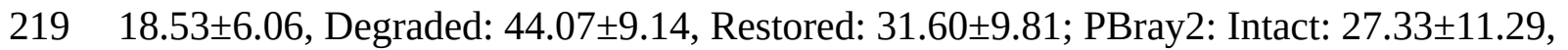

220 Degraded: $71.4 \pm 28.15$, Restored: $52.60 \pm 9.74 ; \mathrm{mg} / \mathrm{kg}$ ) and bulk density (Intact: $0.94 \pm 0.12$,

221 Degraded: 1.32 \pm 0.08 , Restored: $1.15 \pm 0.07 ; \mathrm{g} / \mathrm{ml})$. In comparison, the degraded zone soils

222 showed the lowest $\mathrm{Mg}^{+2}$ levels (Intact: 1038.73 \pm 580.19 , Degraded: $368.93 \pm 180.56$, Restored:

$223789.40 \pm 187.38 ; \mathrm{mg} / \mathrm{kg}$ ) and cation exchange capacity values (Intact: 26.42 \pm 10.32 , Degraded:

$22416.03 \pm 10.95$, Restored: $18.70 \pm 4.12$ ), possibly a reflection of the higher water infiltration rates in

225 the largely unvegetated exposed soils. Unexpectedly, we did not observe significant differences in

$226 \mathrm{NH}_{4}-\mathrm{N}$ (Intact: 51.75 \pm 31.63 , Degraded: 38.32 \pm 7.34 , Restored: 41.66 $\pm 6.51 ; \mathrm{mg} / \mathrm{kg}$; Wilcox test:

227 Intact v. Degraded: $\mathrm{p}=0.74$, Intact v. Restored: $\mathrm{p}=0.55$, Degraded v. Restored: $\mathrm{p}=0.17$ ) or

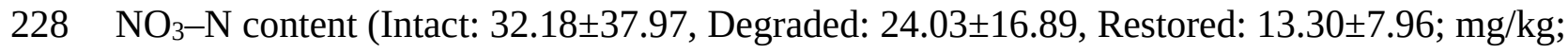

229 Wilcox test: Intact v. Degraded: $\mathrm{p}=0.59$, Intact v. Restored: $\mathrm{p}=0.30$, Degraded v. Restored: $\mathrm{p}=$

230 0.23)between samples from the different zones. These results replicate previous findings for $\mathrm{pH}$

231 and C (Mills \& Fey, 2004b; Lechmere-Oertel, Cowling \& Kerley, 2005) as well as for P, silt and

$232 \mathrm{Mg}$ but not for $\mathrm{Ca}$ and $\mathrm{NH}_{4}-\mathrm{N}$ (Mills \& Fey, 2004b).

233 As expected, the loss of succulent thicket had a major impact on soil temperature buffering and

234 moisture entrapment, which was reflected in significant differences of temperature (Intact:

235 19.73 \pm 7.12 , Degraded: 21.41 \pm 9.45 , Restored: 19.57 \pm 4.95 ; ${ }^{\circ} \mathrm{C}$; Wilcox test: Intact v. Degraded: $\mathrm{p}$

$236=1.07 \times 10^{-9}$, Intact v. Restored: $\mathrm{p}=3.94 \times 10^{-9}$, Degraded v. Restored: $\mathrm{p}=0.02$ ) and relative

237 humidity (Intact: 53.18 \pm 21.40 , Degraded: 58.13 \pm 24.83 , Restored: 60.04 \pm 20.73 ; \%; Wilcox test:

238 Intact v. Degraded: $\mathrm{p}=2.11 \times 10^{-10}$, Intact v. Restored: $\mathrm{p}=9.32 \times 10^{-63}$, Degraded v. Restored: $\mathrm{p}=$

$2398.47 \times 10^{-24}$ ) between the three experimental zones (Table S2 and Fig. S2-S4). The degraded zone

240 had significantly higher maximum daily temperatures than either the intact or restored zones

241 (Intact: 34.40 \pm 8.18 , Degraded: 36.66 \pm 8.68 , Restored: $30.03 \pm 7.43$; ${ }^{\circ} \mathrm{C}$; Wilcox test: Intact v.

242 Degraded: $\mathrm{p}=0.03$, Intact v. Restored: $\mathrm{p}=6.55 \times 10^{-7}$, Degraded v. Restored: $\mathrm{p}=3.21 \times 10^{-11}$;

243 Fig. S3), most likely due to the soil being directly exposed to sunlight, in agreement with

244 observations from similarly degraded thicket landscapes (Lechmere-Oertel et al., 2008). The

245 lower maximum soil temperatures in the restored zone compared to the intact zone (Fig. S3) may

246 be due to greater canopy closure which would buffer soil temperatures.

247 The degraded zone originally displayed a lower daily maximum relative humidity when

248 compared to the intact zone. Following the onset of seasonal rains, the degraded zone exhibited

249 higher daily maximum and minimum relative humidity (Fig. S4). This is unsurprising as there is

250 high rainfall interception in intact thicket canopy ( $60 \%$ interception, amongst the highest values

251 recorded for various vegetation types across the globe (Cowling \& Mills, 2011; van Luijk et al.,

252 2013)) and thus smaller rainfall events have very little impact on soil moisture beneath the intact 
253 thicket canopy relative to the bare ground in the degraded zone. Secondly, the deep lens of low 254 bulk density soil under intact thicket means that water rapidly infiltrates beyond $5 \mathrm{~cm}$ (van Luijk 255 et al., 2013). Thus, the soil moisture under the intact canopy was lower than in the degraded zone 256 for small rainfall events, but water will likely be stored in the leaf litter lens after large rainfall 257 events extending the period of water availability (van Luijk et al., 2013). We suspect that only 258 small ( $<5 \mathrm{~mm}$ ) rainfall events occurred during the period the iButtons were deployed. The

259 restored site lacked the deep litter lens, exhibited a layer of silt trapped from the degraded area 260 and had a more closed canopy than the intact zone, together ensuring that soil relative humidity

261 values were higher than in the degraded and intact zones (Fig. S4).

262 Biodiversity and microbial composition differences between the intact and degraded zones.

263 Alpha-diversity analysis of the 26759 observed ASVs revealed no significant differences in

264 biodiversity between intact and degraded zones (Fig. S5). This was unexpected and contradicts a 265 recent study that found higher levels of diversity in arid soils with plant cover compared to those 266 without (Kushwaha et al., 2021). However, previous studies have disagreed whether herbivory 267 increases (Eldridge et al., 2017) or decreases (Cheng et al., 2016) bacterial diversity and the link 268 between browsing and soil microbial diversity is probably very complex and may depend on both browsing intensity and the plant community species diversity and composition (Qu et al., 2016).

271 Despite the similarities in biodiversity summary statistics, microbial communities from the different zones formed distinct clusters, as indicated by the beta-diversity distances between the samples (Fig. 2B and Fig. S6). Clustering of the microbial populations for the three zones (intact,

273 degraded and restored) captured $15.13 \%$ of the variation in the samples, with restored samples located in an intermediate position between the intact and degraded samples. Together these results suggest that vegetation loss has an impact on the community structure of the succulent thicket soil microbiome, but not on its overall biodiversity.

277 The core microbial community (defined as ASVs present in at least 95\% [i.e. $\geq 33 / 35$ ] of samples: Table S3) only accounted for 103 genus-level ASVs (9.87\%) but comprised $70.29 \%$ of the sequence reads. If the threshold were raised to $100 \%$ (i.e. 35/35 sites), then 60 genus-level ASVs, comprising $5.75 \%$ of the total genus-level ASVs and $54.81 \%$ of the reads, would be detected but if it were lowered to $89 \%$ (i.e. 31/35 sites) then 142 genus-level ASVs comprising $13.60 \%$ of the total genus-level ASVs and $77.84 \%$ of the reads, would be detected. Each of the three sampled zones also had their own unique core communities which showed a level of similar dominance across the reads (Tables S4-S6); the core community accounted for 118 ASVs (13.58\% of genuslevel ASVs, 74.95\% of reads) in the intact zone, 166 ASVs (22.10\% of genus-level ASVs, $88.43 \%$ of reads) in the degraded zone and 207 ASVs (30.49\% of genus-level ASVs, 86.40\% of reads) in the restored zone. If the threshold were raised to $100 \%$ (i.e. $15 / 15$ or $5 / 5$ sites) then the core community would consist of 78 ASVs (8.98\% of genus-level ASVs and $62.75 \%$ of reads) in the intact zone and 121 ASVs (16.11\% of genus-level ASVs and $80.85 \%$ of reads) in the degraded zone while the restored zone would be the same as at the standard $95 \%$ threshold. If the threshold were lowered to $89 \%$ (i.e. $13 / 15$ or $4 / 5$ sites) then the core community would consist of 
294 of genus-level ASVs and 93.74\% of reads) in the restored zone. The dominance of a relatively

295 small number of taxa is a well-known phenomenon in soils (Delgado-Baquerizo et al., 2018). The

296 composite microbial community in all experimental samples comprised 36 prokaryotic phyla, the

297 most abundant of which (based on ASV assignments of 16S rRNA gene amplicon reads) were

298 Actinobacteriota (28.76\%), Proteobacteria (21.39\%), Acidobacteriota (11.40\%), Plantomycetes

299 (9.84\%) and Bacteroidota (7.71\%) (Fig. 3A).

300 Significant differences were observed at the genus level between the intact and degraded zones

301 (Fig. 3B and Fig. S7). The largest differences were observed for Rubrobacter (1.72\% intact

302 versus 6.16\% degraded), Conexibacter (3.57\% intact versus $0.14 \%$ degraded), RB41 (2.22\%

303 intact versus 5.02\% degraded), Bryobacter (4.45\% intact versus 1.82\% degraded) and

304 Mycobacterium (2.69\% intact versus 0.53\% degraded). ASVs with a relative abundance of less

305 than $1 \%$ accounted for between $66.05 \%$ and $69.94 \%$ of all reads in the various zones. Soil

306 samples from the restored zone showed a larger number of taxa classified as 'uncultured' than

307 either the intact or degraded zone samples (4.06\% restored versus $1.50 \%$ intact and $0.29 \%$

308 degraded).

309 In addition, LEfSe analysis identified four biomarker taxa for intact zone soils and five for

310 degraded zone soils (Fig. 4). The intact biomarker taxa were derived from the families

311 Acidobacteriaceae (Subgroup 1) and Myxococcaceae, the order Frankiales and the class

312 Verrucomicrobiae. The order Frankiales is one of the most abundant in the dataset and includes

313 many root-nodule associated taxa (Pawlowski \& Demchenko, 2012; Battenberg et al., 2017); its

314 over-representation in intact sites suggests that the changes in the soil microbiome may be due to

315 the reduction or disappearance of plant-associated taxa with the loss of vegetation. By

316 comparison, biomarker taxa for degraded zone soils were the genera Ensifer and

317 Exiguobacterium, members of which are found in diverse environments (Kasana \& Pandey,

318 2018), the cyanobacterial family Coleofasiculaceae, the order Puniceispiralles and the

319 Chloroflexi class Anaerolineae, commonly found in anaerobic digesters (Xia et al., 2016).

320 Abiotic drivers of microbial community structure in both intact and degraded zones.

321 In order to determine which soil physicochemical properties were important for microbial

322 community structure, we used RDA (Fig. 5). At the phylum level, the ratio of $\mathrm{Ca}$ to $\mathrm{Mg}$ and the

323 soil density explained $47.78 \%$ of the variation in the microbial community (Fig. $5 \mathbf{A}$ ) and, at the

324 genus level, the ratio of $\mathrm{Ca}$ to $\mathrm{Mg}$, the soil density and the soil $\mathrm{pH}$ were able to explain $50.10 \%$ of

325 the variation in the community structure (Fig. 5B, a third axis is not plotted). $\mathrm{pH}$ has frequently

326 been identified as a major driver of bacterial community composition in soils (Rousk et al., 2010;

327 Qu et al., 2016). Contrary to one of the initial expectations of this study, differences in soil

328 relative humidity and temperature resulting from the loss of vegetation did not appear to

329 significant affect microbial community structure in the intact and degraded zones. However, the

330 interplay of relative humidity and temperature may affect the water balance of the soil, which

331 could potentially be responsible for the shift in pH (Slessarev et al., 2016).

332 Unique to near-unique members of the core microbial community in each zone. 
333 To identify unique members of the common core microbial community (Risely, 2020) within

334 each zone, genus-level ASVs were filtered using the following two criteria: the ASVs were

335 present in $>95 \%$ of the sites within a zone and in fewer than $10 \%$ of sites within the other zones

336 (Table S7). The number of near-unique taxa in each zone were also tested at different thresholds

337 to assess how the threshold affected the results (Table S8). The threshold for the number of sites

338 in which an ASV had to present for a specific zone had the greatest effect on the results, while the

339 threshold for the number of non-zone sites in which an ASV could be present only had an effect

340 when the threshold was raised to $20 \%$ or $3 / 15$ sites. While there were several unique core

341 members for the restored zone, there were fewer sites for that zone and all the unique core

342 members were at or below the mean relative abundance of detected taxa; for these reasons the

343 unique core taxa of only the intact and degraded zone samples are discussed.

344 In the intact (vegetated) zone core community, two genera were unique: Acidipila-silvibacterium

345 and Burkholderia-caballeronia-paraburkholderia. Acidipila-silvibacterium is a member of the

346 Acidobacteriota, commonly found in soils and capable of tolerating tolerate low pHs (Kielak et

347 al., 2016; Kalam et al., 2020). The family Acidobacteriaceae (Subgroup 1), which contains

348 Acidipila-silvibacterium, was also identified by LEfSe analysis as a biomarker of intact succulent

349 thicket soil samples (Fig. 4), consistent with the lower mean $\mathrm{pH}$ values of these samples (Intact:

350 pH 5.48, degraded: $\mathrm{pH}$ 6.84). It is likely that the presence of these taxa, almost exclusively in the

351 vegetated soil samples, is due to the abundance of plant biomass, given that Acidipila-

352 silvibacterium has been identified as a core operational taxonomic unit (OTU) of decaying wood

353 (Tláskal et al., 2017) and Burkholderia-caballeronia-paraburkholderia contains many plant-

354 associated species (Compant et al., 2008) which degrade cellulose (Štursová et al., 2012) and are

355 associated with wood-decaying fungi (Christofides et al., 2020).

356 The two unique genera identified in the degraded zone core community were an uncultured

357 member of the order Azospirillales and the genus Arthrobacter. Both of these taxa are potentially

358 nitrogen-fixing (Steenhoudt \& Vanderleyden, 2000; Fernández-González et al., 2017) and

359 Arthrobacter has been implicated in the recovery of polluted soils and soils where vegetation has

360 been lost (Wang, Xie \& Hu, 2013; Kim \& Song, 2014; Fernández-González et al., 2017).

\section{Correlations of taxa in the intact and degraded sites.}

362 In order to understand how the structure of the microbial communities changed between intact

363 and degraded zones, co-occurrence networks of the 50 genus-level ASVs with the highest

364 variation in abundance were filtered from the main dataset and compared between the intact and

365 degraded zones. The network analysis showed a marked decrease in community complexity in

366 degraded compared with intact zone microbiomes (Fig. 6) as measured by clusters of co-

367 occurring taxa. In the intact zone samples, ASVs were grouped in six clusters, whereas in the

368 degraded zone samples, the same ASVs formed only two clusters. The cluster assignments were

369 consistent, even when the number of genus-level ASVs were increased, indicating that the

370 differences in complexity were robust for the ASVs included in the network.

371 In the intact zone network, only positive correlations are observed within groups; surprisingly

372 negative correlations were completely absent. This suggests that the intact zone microbial 
373 community exists in a stable state, where each cluster of taxa may occupy a distinct niche and 374 where inter-taxon competition is minimal. In stark contrast, the degraded zone network showed 375 very large numbers of both positive and negative correlations between the two groups (Fig. 6). A 376 potential ecological implication of this observation is that niches in the degraded zone are largely 377 homogenised, resulting in high levels of inter-taxon competition.

378 A closer examination of the 50 genus-level ASVs showed that 30 had significantly different 379 abundances between the intact and degraded zones (Fig. S8); 15 in cluster 1 and 15 in cluster 2. 380 Thirteen of the 15 nodes belonging to cluster 1 had higher abundance in the intact zone and 13/15 381 nodes belonging to cluster 2 had higher abundance in the degraded zone. The genus-level ASVs 382 found to be higher in the intact zone generally belonged to taxa which have been reported to be 383 plant-associated, such as Connexibacter (Dong et al., 2018; Dobrovolskaya et al., 2020), 384 Mycobacterium (Bouam et al., 2018; Pan et al., 2020), Pseudonocardia (Chen et al., 2009; Zhao 385 et al., 2012; Li et al., 2012) and Microlunatus (Tuo et al., 2016). We note that these plant386 associated taxa were also present in the degraded zone where vegetation is largely absent. It is 387 unclear whether their presence is due to associations with the sparse vegetation, the presence of 388 species in the plant-associated taxon category which do not undergo obligate interactions with 389 plants or bacteria from the intact zone being carried downhill into the degraded zone by rain 390 water (Abu-Ashour \& Lee, 2000; Caillon \& Schelker, 2020).

Although there are known pitfalls in interpreting microbial co-occurrence networks (Armitage \& Jones, 2019; Carr et al., 2019), we suggest that the presence of abundant vegetation (in the intact zone), and the existence of plant- and plant root-associated microbiome niches, likely underlie the observed differences in the two networks (Fig. 6). Plant-root associated niches such as the rhizoplane and rhizospheric zones provide spatial and physicochemical separation for their intrinsic microbial communities (Ofek-Lalzar et al., 2014; Battenberg et al., 2017; Morella et al., 2020); consistent with the well-discriminated clustering structure of the intact zone network, the limited number of inter-cluster correlations and the absence of negative correlations. Conversely, the loss of these defined niche structures in the largely unvegetated degraded zone appears to spatially homogenise the microbial community, leading to a weak clustering structure and a high level of inter-taxon competition.

\section{The intermediate position of the restored zone.}

403 The inclusion of the restored zone, where P. afra had been allowed to regrow, provided the 404 opportunity to evaluate the recovery of the succulent thicket after an $\sim 11$ year interval. Soil 405 samples from the restored zone showed a microbial community that was intermediate between 406 the intact and degraded zones (Fig. 2B). The abundances of some taxa in the restored zone 407 samples were also intermediate between those in the intact and degraded zone samples: e.g. 408 Rubrobacter (Fig. S7). Similarly, a PCA of soil physicochemical properties showed that the restored zone overlapped with both the intact and degraded zones, while the latter two showed no overlap (Fig. 2A). In addition, soil physicochemical properties such as the amount of carbon and soil density (Fig. 5), both mediated by the presence of $P$. afra, were positioned at levels between those of the intact and degraded zones. However, for several other properties, the restored zone samples showed no statistically significant difference from those of the intact or degraded zone. 
414 This may indicate that different properties recover at different rates, but may also be due to 415 stochastic variations between sites.

416 Taken together, these data suggest that the restored zone soils exist in an intermediate state 417 between the intact and degraded zone soils. The obvious implication is that the planting of $P$. afra 418 in degraded zones, as the basis of the restoration program, has resulted in a shift in both the soil 419 properties and microbial communities, from the degraded state to more closely resemble the 420 intact zone. To gain a full understanding of the process of restoration, multiple independent 421 restoration attempts should be established in conjunction with regular, long-term monitoring in 422 order to follow microbial succession (Banning et al., 2011) and distinguish between determined 423 and stochastic events (Zhou \& Ning, 2017). Understanding the temporal nature of community

424 development, together with identification of the functionally important microbial species, would 425 be an important aid to future restoration efforts (Requena et al., 2001; Maestre, Solé \& Singh, 426 2017).

\section{Acknowledgements}

428 The research presented here was part of a BSc (Hons) thesis (MS). We wish to thank Timm

429 Hoffman for providing repeat photographs of the study site (used in Figure S1).

\section{References}

Abu-Ashour J, Lee H. 2000. Transport of bacteria on sloping soil surfaces by runoff.

Environmental Toxicology 15:149-153. DOI: 10.1002/(SICI)1522-

7278(2000)15:2<149::AID-TOX11>3.0.CO;2-O.

Ahlmann-Eltze C. 2019. ggsignif: Significance Brackets for “ggplot2.”

Armitage DW, Jones SE. 2019. How sample heterogeneity can obscure the signal of microbial interactions. The ISME Journal 13:2639-2646. DOI: 10.1038/s41396-019-0463-3.

Auguie B. 2017. gridExtra: Miscellaneous Functions for “Grid” Graphics.

Banning NC, Gleeson DB, Grigg AH, Grant CD, Andersen GL, Brodie EL, Murphy DV. 2011.

Soil Microbial Community Successional Patterns during Forest Ecosystem Restoration.

Applied and Environmental Microbiology 77:6158-6164. DOI: 10.1128/AEM.00764-11.

Bardgett RD, van der Putten WH. 2014. Belowground biodiversity and ecosystem functioning.

Nature 515:505-511. DOI: 10.1038/nature13855.

Battenberg K, Wren JA, Hillman J, Edwards J, Huang L, Berry AM. 2017. The Influence of the Host Plant Is the Major Ecological Determinant of the Presence of Nitrogen-Fixing Root 
Nodule Symbiont Cluster II Frankia Species in Soil. Applied and Environmental Microbiology 83:e02661-16, e02661-16. DOI: 10.1128/AEM.02661-16.

Birch HF. 1958. The effect of soil drying on humus decomposition and nitrogen availability.

Plant and Soil 10:9-31. DOI: 10.1007/BF01343734.

Bolyen E, Rideout JR, Dillon MR, Bokulich NA, Abnet CC, Al-Ghalith GA, Alexander H, Alm EJ, Arumugam M, Asnicar F, Bai Y, Bisanz JE, Bittinger K, Brejnrod A, Brislawn CJ, Brown CT, Callahan BJ, Caraballo-Rodríguez AM, Chase J, Cope EK, Da Silva R, Diener C, Dorrestein PC, Douglas GM, Durall DM, Duvallet C, Edwardson CF, Ernst M, Estaki M, Fouquier J, Gauglitz JM, Gibbons SM, Gibson DL, Gonzalez A, Gorlick K, Guo J, Hillmann B, Holmes S, Holste H, Huttenhower C, Huttley GA, Janssen S, Jarmusch AK, Jiang L, Kaehler BD, Kang KB, Keefe CR, Keim P, Kelley ST, Knights D, Koester I, Kosciolek T, Kreps J, Langille MGI, Lee J, Ley R, Liu Y-X, Loftfield E, Lozupone C, Maher M, Marotz C, Martin BD, McDonald D, McIver LJ, Melnik AV, Metcalf JL, Morgan SC, Morton JT, Naimey AT, Navas-Molina JA, Nothias LF, Orchanian SB, Pearson T, Peoples SL, Petras D, Preuss ML, Pruesse E, Rasmussen LB, Rivers A, Robeson MS, Rosenthal P, Segata N, Shaffer M, Shiffer A, Sinha R, Song SJ, Spear JR, Swafford AD, Thompson LR, Torres PJ, Trinh P, Tripathi A, Turnbaugh PJ, Ul-Hasan S, van der Hooft JJJ, Vargas F, Vázquez-Baeza Y, Vogtmann E, von Hippel M, Walters W, Wan Y, Wang M, Warren J, Weber KC, Williamson CHD, Willis AD, Xu ZZ, Zaneveld JR, Zhang Y, Zhu Q, Knight R, Caporaso JG. 2019. Reproducible, interactive, scalable and extensible microbiome data science using QIIME 2. Nature Biotechnology 37:852857. DOI: 10.1038/s41587-019-0209-9.

Bouam A, Armstrong N, Levasseur A, Drancourt M. 2018. Mycobacterium terramassiliense, Mycobacterium rhizamassiliense and Mycobacterium numidiamassiliense sp. nov., three new Mycobacterium simiae complex species cultured from plant roots. Scientific Reports 8:9309. DOI: 10.1038/s41598-018-27629-1. 
Brodie E, Edwards S, Clipson N. 2002. Bacterial Community Dynamics across a Floristic Gradient in a Temperate Upland Grassland Ecosystem. Microbial Ecology 44:260-270. DOI: $10.1007 / \mathrm{s} 00248-002-2012-1$.

Caillon F, Schelker J. 2020. Dynamic transfer of soil bacteria and dissolved organic carbon into small streams during hydrological events. Aquatic Sciences 82:41. DOI: 10.1007/s00027020-0714-4.

Callahan BJ, McMurdie PJ, Holmes SP. 2017. Exact sequence variants should replace operational taxonomic units in marker-gene data analysis. ISME Journal 11:2639-2643. DOI: 10.1038/ismej.2017.119.

Callahan BJ, McMurdie PJ, Rosen MJ, Han AW, Johnson AJA, Holmes SP. 2016. DADA2: Highresolution sample inference from Illumina amplicon data. Nature Methods 13:581-583. DOI: $10.1038 /$ nmeth.3869.

Carr A, Diener C, Baliga NS, Gibbons SM. 2019. Use and abuse of correlation analyses in microbial ecology. The ISME Journal 13:2647-2655. DOI: 10.1038/s41396-019-0459-z.

Chen H-H, Qin S, Li J, Zhang Y-Q, Xu L-H, Jiang C-L, Kim C-J, Li W-J. 2009. Pseudonocardia endophytica sp. nov., isolated from the pharmaceutical plant Lobelia clavata. International Journal of Systematic and Evolutionary Microbiology, 59:559-563.

Cheng J, Jing G, Wei L, Jing Z. 2016. Long-term grazing exclusion effects on vegetation characteristics, soil properties and bacterial communities in the semi-arid grasslands of China. Ecological Engineering 97:170-178. DOI: 10.1016/j.ecoleng.2016.09.003.

Christofides SR, Bettridge A, Farewell D, Weightman AJ, Boddy L. 2020. The influence of migratory Paraburkholderia on growth and competition of wood-decay fungi. Fungal Ecology 45:100937. DOI: 10.1016/j.funeco.2020.100937.

Clauset A, Newman MEJ, Moore C. 2004. Finding community structure in very large networks. Physical Review E 70:066111. DOI: 10.1103/PhysRevE.70.066111.

Compant S, Nowak J, Coenye T, Clément C, Ait Barka E. 2008. Diversity and occurrence of Burkholderia spp. in the natural environment. FEMS Microbiology Reviews 32:607-626. DOI: 10.1111/j.1574-6976.2008.00113.x. 
Cowling RM. 1983. Phytochorology and Vegetation History in the South-Eastern Cape, South Africa. Journal of Biogeography 10:393. DOI: 10.2307/2844748.

Cowling RM, Mills AJ. 2011. A preliminary assessment of rain throughfall beneath Portulacaria afra canopy in subtropical thicket and its implications for soil carbon stocks. South African Journal of Botany 77:236-240. DOI: 10.1016/j.sajb.2010.06.004.

Cowling RM, Potts AJ. 2015. Climatic, edaphic and fire regime determinants of biome boundaries in the eastern Cape Floristic Region. South African Journal of Botany 101:7381. DOI: 10.1016/j.sajb.2015.03.182.

Cowling RM, Procheş Ş, Vlok JHJ, van Staden J. 2005. On the origin of southern African subtropical thicket vegetation. South African Journal of Botany 71:1-23. DOI: 10.1016/S0254-6299(15)30144-7.

Dayaram A, Harris LR, Grobler BA, Van der Merwe S, Rebelo AG, Ward Powrie L, Vlok JHJ, Desmet PG, Qabaqaba M, Hlahane KM, Skowno AL. 2019. Vegetation Map of South Africa, Lesotho and Swaziland 2018: A description of changes since 2006. Bothalia 49. DOI: 10.4102/abc.v49i1.2452.

Delgado-Baquerizo M, Oliverio AM, Brewer TE, Benavent-González A, Eldridge DJ, Bardgett RD, Maestre FT, Singh BK, Fierer N. 2018. A global atlas of the dominant bacteria found in soil. Science 359:320-325. DOI: 10.1126/science.aap9516.

Dobrovolskaya TG, Golovchenko AV, Lysak LV, Yurchenko EN. 2020. Taxonomic Structure of Bacterial Communities of Rhizospheric Soil under Bogs’ Plants. Moscow University Soil Science Bulletin 75:93-100. DOI: 10.3103/S0147687420020039.

Dong L, Cheng R, Xiao L, Wei F, Wei G, Xu J, Wang Y, Guo X, Chen Z, Chen S. 2018. Diversity and composition of bacterial endophytes among plant parts of Panax notoginseng. Chinese Medicine 13:41. DOI: 10.1186/s13020-018-0198-5.

Duker R, Cowling RM, du Preez DR, Potts AJ. 2015a. Frost, Portulacaria afra Jacq., and the boundary between the Albany Subtropical Thicket and Nama-Karoo biomes. South African Journal of Botany 101:112-119. DOI: 10.1016/j.sajb.2015.05.004. 
Duker R, Cowling RM, du Preez DR, van der Vyver ML, Weatherall-Thomas CR, Potts AJ. 2015b. Community-level assessment of freezing tolerance: frost dictates the biome boundary between Albany subtropical thicket and Nama-Karoo in South Africa. Journal of Biogeography 42:167-178. DOI: 10.1111/jbi.12415.

Eldridge DJ, Delgado-Baquerizo M, Travers SK, Val J, Oliver I, Hamonts K, Singh BK. 2017. Competition drives the response of soil microbial diversity to increased grazing by vertebrate herbivores. Ecology 98:1922-1931. DOI: 10.1002/ecy.1879.

Faust K, Sathirapongsasuti JF, Izard J, Segata N, Gevers D, Raes J, Huttenhower C. 2012. Microbial Co-occurrence Relationships in the Human Microbiome. PLoS Computational Biology 8:e1002606. DOI: 10.1371/journal.pcbi.1002606.

Fernández-González AJ, Martínez-Hidalgo P, Cobo-Díaz JF, Villadas PJ, Martínez-Molina E, Toro N, Tringe SG, Fernández-López M. 2017. The rhizosphere microbiome of burned holm-oak: potential role of the genus Arthrobacter in the recovery of burned soils. Scientific Reports 7:6008. DOI: 10.1038/s41598-017-06112-3.

Garbeva P, Postma J, van Veen JA, van Elsas JD. 2006. Effect of above-ground plant species on soil microbial community structure and its impact on suppression of Rhizoctonia solani AG3. Environmental Microbiology 8:233-246. DOI: 10.1111/j.1462-2920.2005.00888.x. Grayston SJ, Campbell CD, Bardgett RD, Mawdsley JL, Clegg CD, Ritz K, Griffiths BS, Rodwell JS, Edwards SJ, Davies WJ, Elston DJ, Millard P. 2004. Assessing shifts in microbial community structure across a range of grasslands of differing management intensity using CLPP, PLFA and community DNA techniques. Applied Soil Ecology 25:63-84. DOI: 10.1016/S0929-1393(03)00098-2.

Grolemund G, Wickham H. 2011. Dates and Times Made Easy with lubridate. Journal of Statistical Software 40. DOI: 10.18637/jss.v040.i03.

Guralnick LJ, Rorabaugh PA, Hanscom Z. 1984. Influence of Photoperiod and Leaf Age on Crassulacean Acid Metabolism in Portulacaria afra (L.) Jacq. Plant Physiology 75:454457. DOI: $10.1104 /$ pp.75.2.454. 
Guralnick LJ, Ting IP. 1987. Physiological Changes in Portulacaria afra (L.) Jacq. during a Summer Drought and Rewatering. Plant Physiology 85:481-486. DOI:

10.1104/pp.85.2.481.

Hoare DB, Mucina L, Rutherford MC, Volk JHJ, Euston-Brown DIW, Palmer AR, Powrie LW, Lechmere-Oertel RG, Proches SM, Dold AP, Ward RA. 2006. Albany Thicket Biome. Strelitzia 19:541-567.

Jansson JK, Hofmockel KS. 2020. Soil microbiomes and climate change. Nature Reviews Microbiology 18:35-46. DOI: 10.1038/s41579-019-0265-7.

Jenkinson DS. 1981. The fate of plant and animal residues in soil. In: The Chemistry of Soil Processes. New York: John Wiley and Sons, 505-561.

Kalam S, Basu A, Ahmad I, Sayyed RZ, El-Enshasy HA, Dailin DJ, Suriani NL. 2020. Recent Understanding of Soil Acidobacteria and Their Ecological Significance: A Critical Review. Frontiers in Microbiology 11:580024. DOI: 10.3389/fmicb.2020.580024. Kasana RC, Pandey CB. 2018. Exiguobacterium 
Kushwaha P, Neilson JW, Barberán A, Chen Y, Fontana CG, Butterfield BJ, Maier RM. 2021. Arid Ecosystem Vegetation Canopy-Gap Dichotomy: Influence on Soil Microbial Composition and Nutrient Cycling Functional Potential. Applied and Environmental Microbiology 87. DOI: 10.1128/AEM.02780-20.

Lechmere-Oertel RG, Cowling RM, Kerley GIH. 2005. Landscape dysfunction and reduced spatial heterogeneity in soil resources and fertility in semi-arid succulent thicket, South Africa. Austral Ecology 30:615-624. DOI: 10.1111/j.1442-9993.2005.01495.x.

Lechmere-Oertel RG, Kerley GIH, Cowling RM. 2005. Patterns and implications of transformation in semi-arid succulent thicket, South Africa. Journal of Arid Environments 62:459-474. DOI: 10.1016/j.jaridenv.2004.11.016.

Lechmere-Oertel RG, Kerley GIH, Mills AJ, Cowling RM. 2008. Litter dynamics across browsing-induced fenceline contrasts in succulent thicket, South Africa. South African Journal of Botany 74:651-659. DOI: 10.1016/j.sajb.2008.04.002.

Li J, Zhao G-Z, Varma A, Qin S, Xiong Z, Huang H-Y, Zhu W-Y, Zhao L-X, Xu L-H, Zhang S, Li W-J. 2012. An Endophytic Pseudonocardia Species Induces the Production of Artemisinin in Artemisia annua. PLoS ONE 7:e51410. DOI:

10.1371/journal.pone.0051410.

Lloyd J, Berg E, Palmer A. 2002. Patterns of Transformation and Degradation in the Thicket Biome, South Africa.

van Luijk G, Cowling RM, Riksen MJPM, Glenday J. 2013. Hydrological implications of desertification: Degradation of South African semi-arid subtropical thicket. Journal of Arid Environments 91:14-21. DOI: 10.1016/j.jaridenv.2012.10.022.

Maestre FT, Solé R, Singh BK. 2017. Microbial biotechnology as a tool to restore degraded drylands. Microbial Biotechnology 10:1250-1253. DOI: 10.1111/1751-7915.12832.

Marschner P. 2003. Structure and function of the soil microbial community in a long-term fertilizer experiment. Soil Biology and Biochemistry 35:453-461. DOI: 10.1016/S00380717(02)00297-3. 
McCrackin ML, Harms TK, Grimm NB, Hall SJ, Kaye JP. 2008. Responses of soil microorganisms to resource availability in urban, desert soils. Biogeochemistry 87:143155. DOI: 10.1007/s10533-007-9173-4.

McKnight DT, Huerlimann R, Bower DS, Schwarzkopf L, Alford RA, Zenger KR. 2019. Methods for normalizing microbiome data: An ecological perspective. Methods in Ecology and Evolution 10:389-400. DOI: 10.1111/2041-210X.13115.

McMurdie PJ, Holmes S. 2013. phyloseq: An R Package for Reproducible Interactive Analysis and Graphics of Microbiome Census Data. PLoS ONE 8:e61217. DOI: 10.1371/journal.pone.0061217.

Mills AJ, Cowling RM. 2006. Rate of Carbon Sequestration at Two Thicket Restoration Sites in the Eastern Cape, South Africa. Restoration Ecology 14:38-49. DOI: 10.1111/j.1526100X.2006.00103.x.

Mills AJ, Cowling RM. 2010. Below-ground carbon stocks in intact and transformed subtropical thicket landscapes in semi-arid South Africa. Journal of Arid Environments 74:93-100. DOI: 10.1016/j.jaridenv.2009.07.002.

Mills AJ, Cowling RM, Fey MV, Kerley GIH, Donaldson JS, Lechmere-Oertel RG, Sigwela AM, Skowno AL, Rundel P. 2005. Effects of goat pastoralism on ecosystem carbon storage in semiarid thicket, Eastern Cape, South Africa. Austral Ecology 30:797-804. DOI: 10.1111/ j.1442-9993.2005.01523.x.

Mills AJ, Fey MV. 2004a. Frequent fires intensify soil crusting: physicochemical feedback in the pedoderm of long-term burn experiments in South Africa. Geoderma 121:45-64. DOI: 10.1016/j.geoderma.2003.10.004.

Mills A, Fey M. 2004b. Transformation of thicket to savanna reduces soil quality in the Eastern Cape, South Africa. Plant and Soil 265:153-163. DOI: 10.1007/s11104-005-0534-2.

Mills AJ, Robson A. 2017. Survivorship of spekboom (Portulacaria afra) planted within the Subtropical Thicket Restoration Programme. South African Journal of Science 113. DOI: 10.17159/sajs.2017/a0196. 
Mills AJ, Spear D, Ndhlovu T, Knight MH, Peinke DM, Hofmeyr S, Cowling RM. 2014. Biomass of large herbivores in South African subtropical thicket. African Journal of Ecology 52:577-580. DOI: 10.1111/aje.12162.

Mills A, Vyver M, Gordon I, Patwardhan A, Marais C, Blignaut J, Sigwela A, Kgope B. 2015. Prescribing Innovation within a Large-Scale Restoration Programme in Degraded Subtropical Thicket in South Africa. Forests 6:4328-4348. DOI: 10.3390/f6114328.

Moolman HJ, Cowling RM. 1994. The impact of elephant and goat grazing on the endemic flora of South African succulent thicket. Biological Conservation 68:53-61. DOI: 10.1016/0006-3207(94)90546-0.

Morella NM, Weng FC-H, Joubert PM, Metcalf CJE, Lindow S, Koskella B. 2020. Successive passaging of a plant-associated microbiome reveals robust habitat and host genotypedependent selection. Proceedings of the National Academy of Sciences 117:1148-1159. DOI: 10.1073/pnas.1908600116.

Neuwirth E. 2014. RColorBrewer: ColorBrewer Palettes.

Ofek-Lalzar M, Sela N, Goldman-Voronov M, Green SJ, Hadar Y, Minz D. 2014. Niche and hostassociated functional signatures of the root surface microbiome. Nature Communications 5:4950. DOI: $10.1038 /$ ncomms5950.

Oksanen J, Blanchet FG, Friendly M, Kindt R, Legendre P, McGlinn D, Minchin PR, O’Hara RB, Simpson GL, Solymos P, Stevens MHH, Szoecs E, Wagner H. 2019. vegan: Community Ecology Package.

Pan L, Chen J, Ren S, Shen H, Rong B, Liu W, Yang Z. 2020. Complete genome sequence of Mycobacterium Mya-zh01, an endophytic bacterium, promotes plant growth and seed germination isolated from flower stalk of Doritaenopsis. Archives of Microbiology 202:1965-1976. DOI: 10.1007/s00203-020-01924-w.

Pawlowski K, Demchenko KN. 2012. The diversity of actinorhizal symbiosis. Protoplasma 249:967-979. DOI: 10.1007/s00709-012-0388-4. 
Peschel S, Müller CL, von Mutius E, Boulesteix A-L, Depner M. 2020. NetCoMi: Network Construction and Comparison for Microbiome Data in R. bioRxiv. DOI: 10.1101/2020.07.15.195248.

Qu T, Du W, Yuan X, Yang Z, Liu D, Wang D, Yu L. 2016. Impacts of Grazing Intensity and Plant Community Composition on Soil Bacterial Community Diversity in a Steppe Grassland. PLOS ONE 11:e0159680. DOI: 10.1371/journal.pone.0159680.

Quast C, Pruesse E, Yilmaz P, Gerken J, Schweer T, Yarza P, Peplies J, Glöckner FO. 2013. The SILVA ribosomal RNA gene database project: improved data processing and web-based tools. Nucleic Acids Research 41:D590-D596. DOI: 10.1093/nar/gks1219.

R Core Team. 2020. R: A Language and Environment for Statistical Computing. Vienna, Austria: R Foundation for Statistical Computing.

Requena N, Perez-Solis E, Azcón-Aguilar C, Jeffries P, Barea J-M. 2001. Management of Indigenous Plant-Microbe Symbioses Aids Restoration of Desertified Ecosystems. Applied and Environmental Microbiology 67:495-498. DOI: 10.1128/AEM.67.2.495498.2001.

Risely A. 2020. Applying the core microbiome to understand host-microbe systems. Journal of Animal Ecology 89:1549-1558. DOI: 10.1111/1365-2656.13229.

Rousk J, Bååth E, Brookes PC, Lauber CL, Lozupone C, Caporaso JG, Knight R, Fierer N. 2010. Soil bacterial and fungal communities across a $\mathrm{pH}$ gradient in an arable soil. The ISME Journal 4:1340-1351. DOI: 10.1038/ismej.2010.58.

Segata N, Izard J, Waldron L, Gevers D, Miropolsky L, Garrett WS, Huttenhower C. 2011. Metagenomic biomarker discovery and explanation. Genome Biology 12:R60-R60. DOI: 10.1186/gb-2011-12-6-r60.

Sigwela AM, Kerley GIH, Mills AJ, Cowling RM. 2009. The impact of browsing-induced degradation on the reproduction of subtropical thicket canopy shrubs and trees. South African Journal of Botany 75:262-267. DOI: 10.1016/j.sajb.2008.12.001. 
Slessarev EW, Lin Y, Bingham NL, Johnson JE, Dai Y, Schimel JP, Chadwick OA. 2016. Water balance creates a threshold in soil pH at the global scale. Nature 540:567-569. DOI: 10.1038/nature20139.

Slowikowski K. 2021. ggrepel: Automatically Position Non-Overlapping Text Labels with “ggplot2."

Steenhoudt O, Vanderleyden J. 2000. Azospirillum, a free-living nitrogen-fixing bacterium closely associated with grasses: genetic, biochemical and ecological aspects. FEMS Microbiology Reviews 24:487-506. DOI: 10.1111/j.1574-6976.2000.tb00552.x.

Štursová M, Žifčáková L, Leigh MB, Burgess R, Baldrian P. 2012. Cellulose utilization in forest litter and soil: identification of bacterial and fungal decomposers. FEMS Microbiology Ecology 80:735-746. DOI: 10.1111/j.1574-6941.2012.01343.x.

Ting IP, Hanscom Z. 1977. Induction of Acid Metabolism in Portulacaria afra. Plant Physiology 59:511-514. DOI: 10.1104/pp.59.3.511.

Tláskal V, Zrůstová P, Vrška T, Baldrian P. 2017. Bacteria associated with decomposing dead wood in a natural temperate forest. FEMS Microbiology Ecology 93. DOI: 10.1093/femsec/fix157.

Todkill W, Kerley G, Campbell E. 2006. Brushpiles and dung as rehabilitation patches: effect on soil resources in degraded succulent thicket, Eastern Cape, South Africa. African Journal of Range \& Forage Science 23:39-48. DOI: 10.2989/10220110609485885.

Tuo L, Li J, Liu S-W, Liu Y, Hu L, Chen L, Jiang M-G, Sun C-H. 2016. Microlunatus endophyticus sp. nov., an endophytic actinobacterium isolated from bark of Bruguiera sexangula. International Journal of Systematic and Evolutionary Microbiology 66:481486. DOI: 10.1099/ijsem.0.000779.

Ulrich A, Becker R. 2006. Soil parent material is a key determinant of the bacterial community structure in arable soils: Community structure affected by soil parent material. FEMS Microbiology Ecology 56:430-443. DOI: 10.1111/j.1574-6941.2006.00085.x.

Vlok JHJ, Euston-Brown DIW, Cowling RM. 2003. Acocks’ Valley Bushveld 50 years on: new perspectives on the delimitation, characterisation and origin of subtropical thicket 
vegetation. South African Journal of Botany 69:27-51. DOI: 10.1016/S02546299(15)30358-6.

van der Vyver ML, Cowling RM. 2019. Aboveground biomass and carbon pool estimates of Portulacaria afra (spekboom)-rich subtropical thicket with species-specific allometric models. Forest Ecology and Management 448:11-21. DOI: 10.1016/j.foreco.2019.05.048. van der Vyver ML, Mills AJ, Cowling RM. 2021. A biome-wide experiment to assess the effects of propagule size and treatment on the survival of Portulacaria afra (spekboom) truncheons planted to restore degraded subtropical thicket of South Africa. PLOS ONE 16:e0250256. DOI: 10.1371/journal.pone.0250256.

Wang Q, Xie S, Hu R. 2013. Bioaugmentation with Arthrobacter sp. strain DAT1 for remediation of heavily atrazine-contaminated soil. International Biodeterioration \& Biodegradation 77:63-67. DOI: 10.1016/j.ibiod.2012.11.003.

Wickham H. 2016. ggplot2: Elegant Graphics for Data Analysis. Springer-Verlag New York. Wickham H. 2019. stringr: Simple, Consistent Wrappers for Common String Operations. Wilman V, Campbell EE, Potts AJ, Cowling RM. 2014. A mismatch between germination requirements and environmental conditions: Niche conservatism in xeric subtropical thicket canopy species? South African Journal of Botany 92:1-6. DOI: 10.1016/j.sajb.2013.12.007.

Xia Y, Wang Y, Wang Y, Chin FYL, Zhang T. 2016. Cellular adhesiveness and cellulolytic capacity in Anaerolineae revealed by omics-based genome interpretation. Biotechnology for Biofuels 9:111. DOI: 10.1186/s13068-016-0524-z.

Xun W, Yan R, Ren Y, Jin D, Xiong W, Zhang G, Cui Z, Xin X, Zhang R. 2018. Grazing-induced microbiome alterations drive soil organic carbon turnover and productivity in meadow steppe. Microbiome 6:170. DOI: 10.1186/s40168-018-0544-y.

Yilmaz P, Parfrey LW, Yarza P, Gerken J, Pruesse E, Quast C, Schweer T, Peplies J, Ludwig W, Glöckner FO. 2014. The SILVA and “All-species Living Tree Project (LTP)” taxonomic frameworks. Nucleic Acids Research 42:D643-D648. DOI: 10.1093/nar/gkt1209. 
Zhao G-Z, Li J, Qin Y-L, Miao C-P, Wei D-Q, Zhang S, Xu L-H, Li W-J. 2012. Pseudonocardia antimicrobica sp. nov., a novel endophytic actinomycete associated with Artemisia annua L. (sweet wormwood). The Journal of Antibiotics 65:469-472. DOI: 10.1038/ja.2012.56.

Zhou J, Ning D. 2017. Stochastic Community Assembly: Does It Matter in Microbial Ecology? Microbiology and Molecular Biology Reviews 81:e00002-17, e00002-17. DOI: 10.1128/ MMBR.00002-17.

431 


\section{Figure 1}

The layout and appearance of the study site.

(A) The layout of the study site as seen in Google Earth Pro. Sampling sites numbered 1-3 occur in the intact succulent thicket while sites 4-6 occur in the degraded succulent thicket. P1-P5 are in the restored zone. The side panels show photographs taken at $(B+C)$ intact and $(D+E)$ degraded sampling sites. See Fig. S1 for further historical imagery of the site

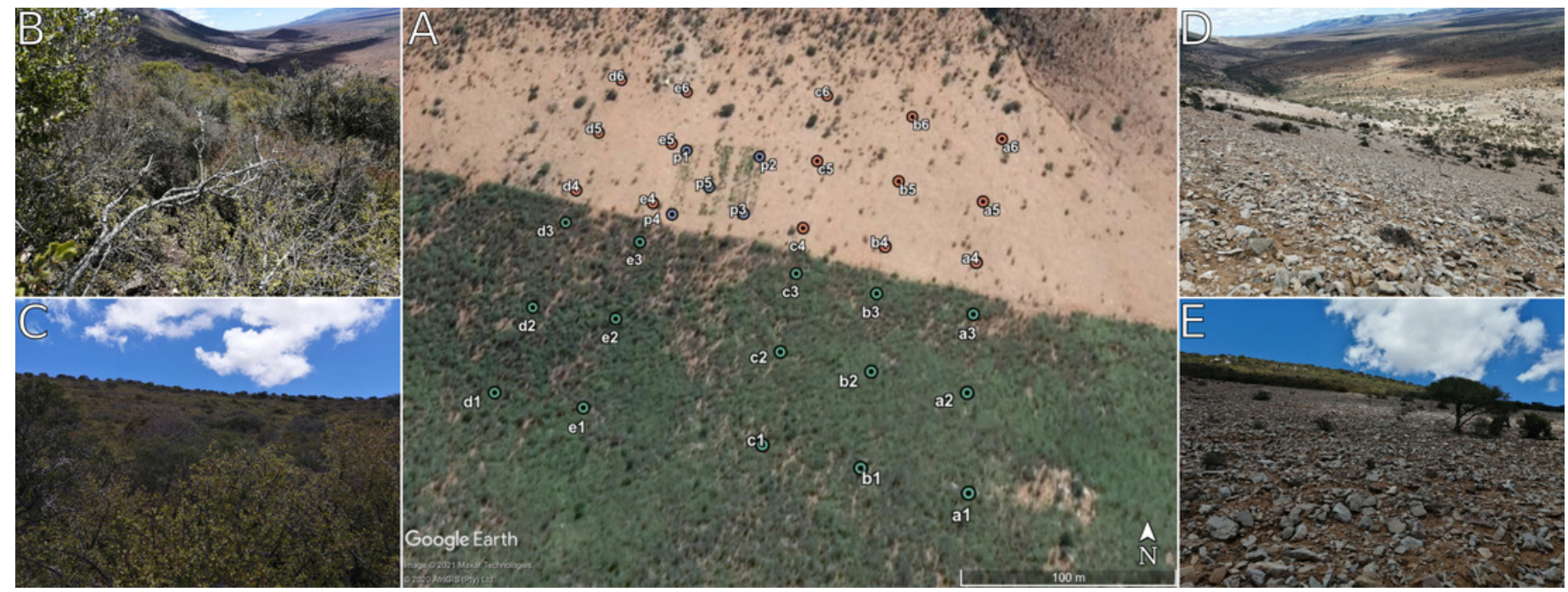




\section{Figure 2}

Comparison of the different vegetation zones through Principal Components Analysis (PCA) and Principal Co-ordinates Analysis (PCOA).

(A) Principal Components Analysis (PCA) of the soil physicochemistry demonstrating a separation between the intact and degraded soils with restored soils overlapping with the other two zones. The variables, their relative weights and directions are shown as black arrows. The first two principal components contain $45.36 \%$ of the variation. (B) Principal Coordinates Analysis (PCOA) using weighted Jaccard distances based on ASV composition showing that the samples from different zones group together without overlap. When grouped by zone, the PCoA explains $15.13 \%$ of the variation.

A

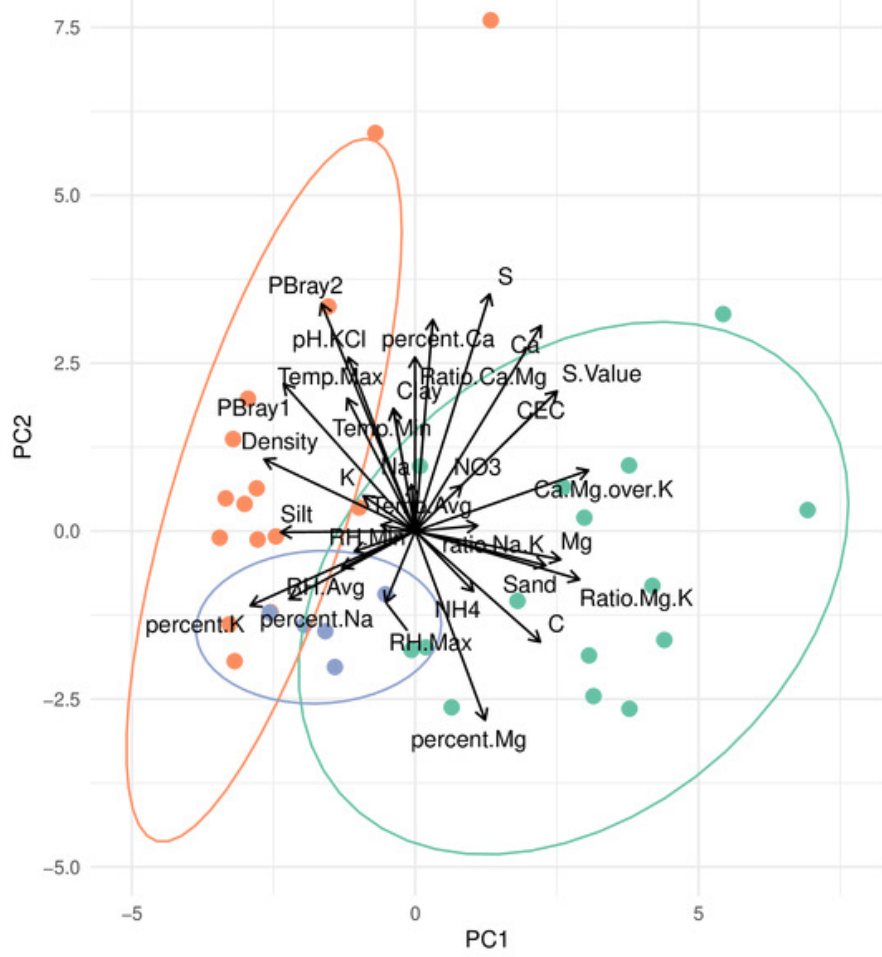

B

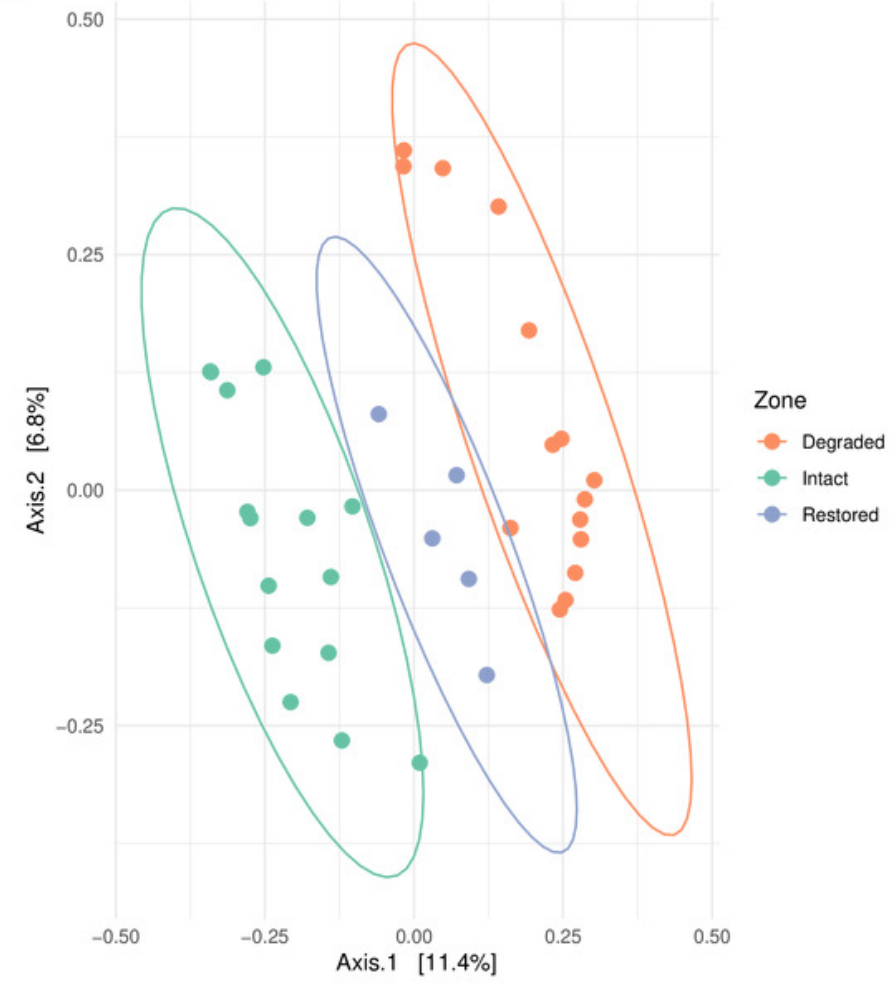




\section{Figure 3}

Relative abundance of bacterial taxa.

Relative abundance of (A) bacterial phyla and (B) genera. Taxa which have a relative abundance less than $1 \%$ are combined in the NA category in $(A)$ and are completely removed in (B) for ease of viewing. The taxa displayed in (B) account for approximately $25 \%$ of the total abundance in the samples.
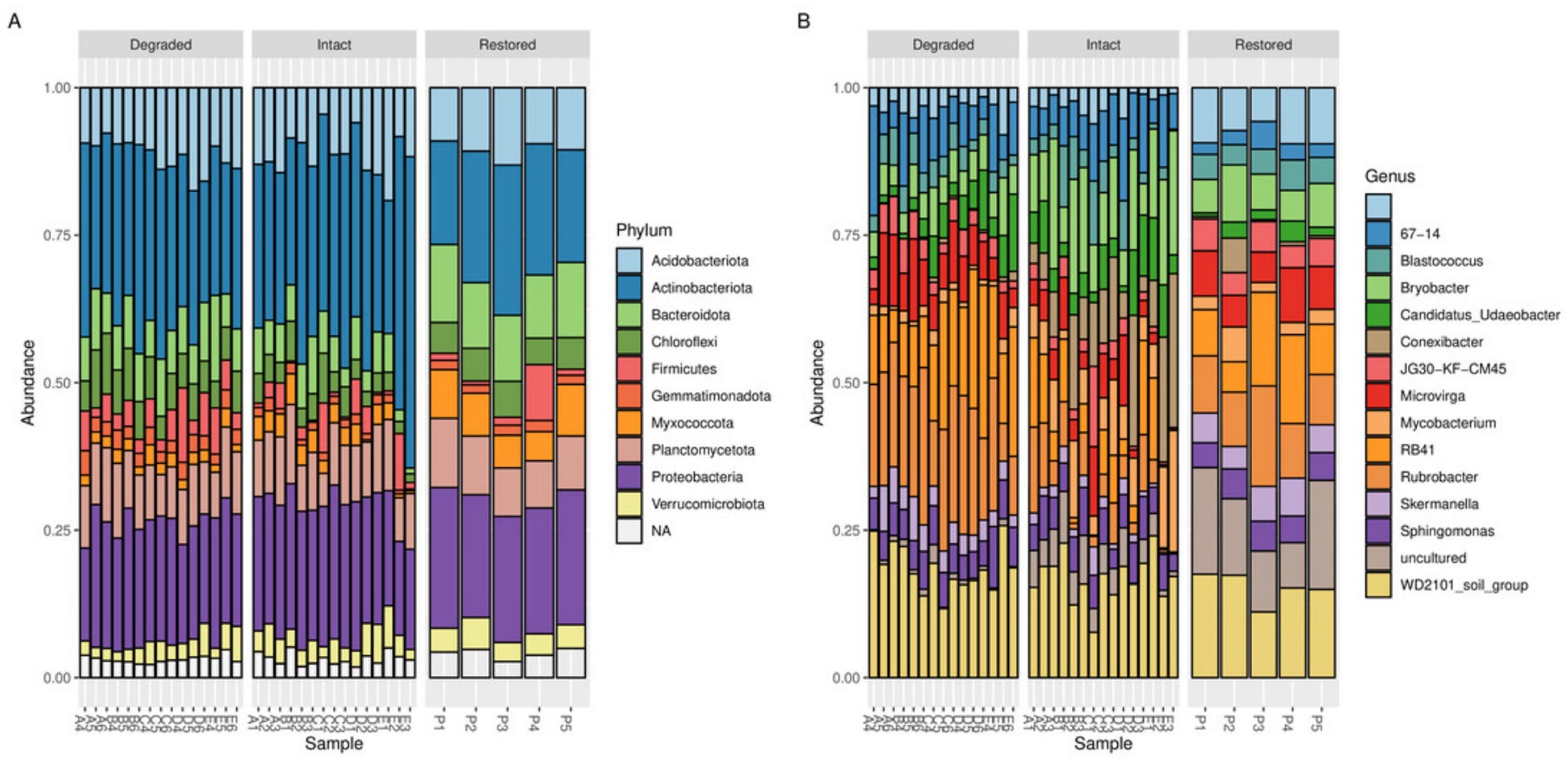
Figure 4

Taxa identified as potential biomarkers.

Taxa identified as potential biomarkers according to LEfSe analysis. Only the lowest taxa in the hierarchy is displayed for a particular condition. Taxa were identified as biomarkers for $(A-E)$ degraded vegetation, $(F-I)$ intact vegetation or $(J-P)$ restored vegetation.

A

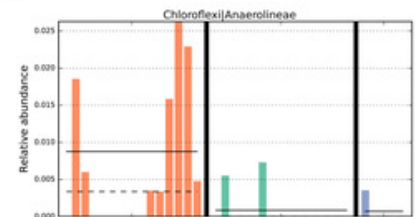

E
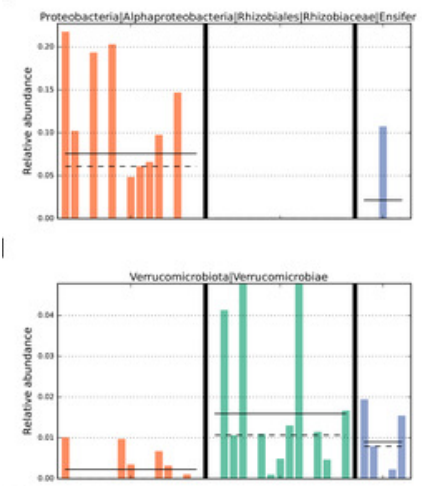

M

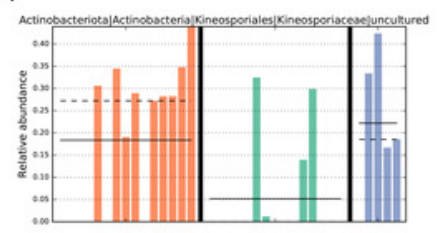

B

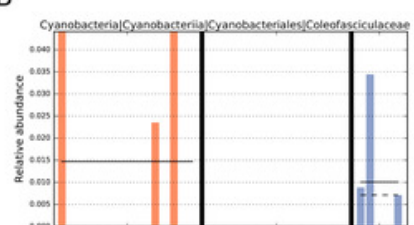

$\mathrm{F}$

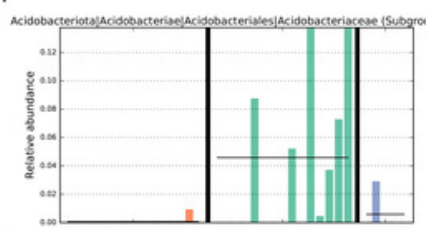

J

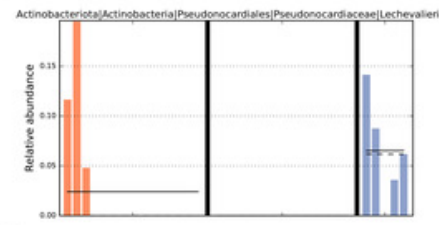

$\mathrm{N}$

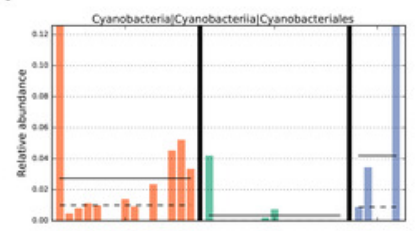

C

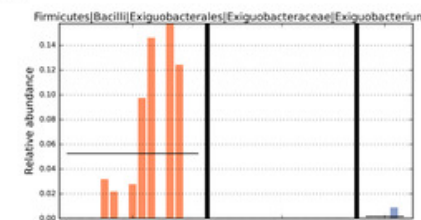

G

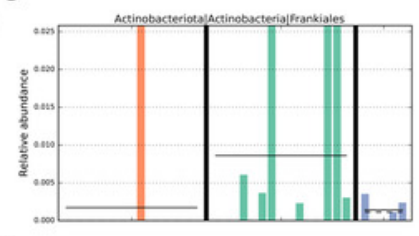

K

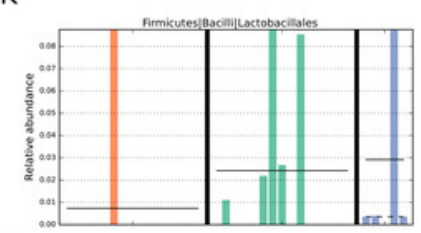

$\mathrm{O}$

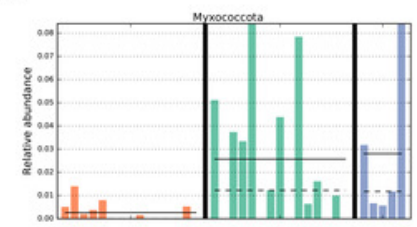

D

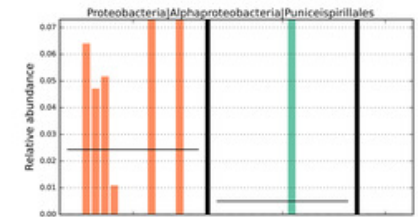

$\mathrm{H}$

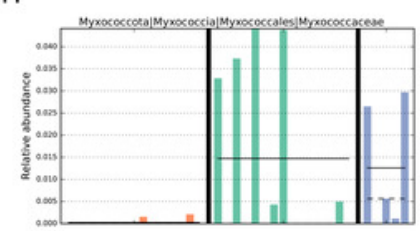

L

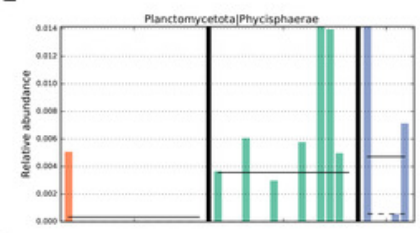

P

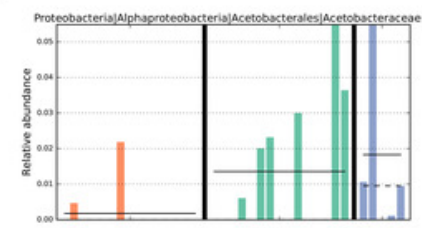




\section{Figure 5}

Redundancy analysis and associated soil physicochemistry.

On the top row are the RDA results when assessing the communities at the (A) phylum and

(B) genus level. Only a limited number of taxa names are displayed to prevent label overlap.

The bottom row shows box-and-whisker plots of the variables which were determined to play a significant role in the RDA; (C) pH, (D) ratio of $\mathrm{Ca}$ to $\mathrm{Mg}$ and (E) density. Significance was determined using the Wilcox test.

A

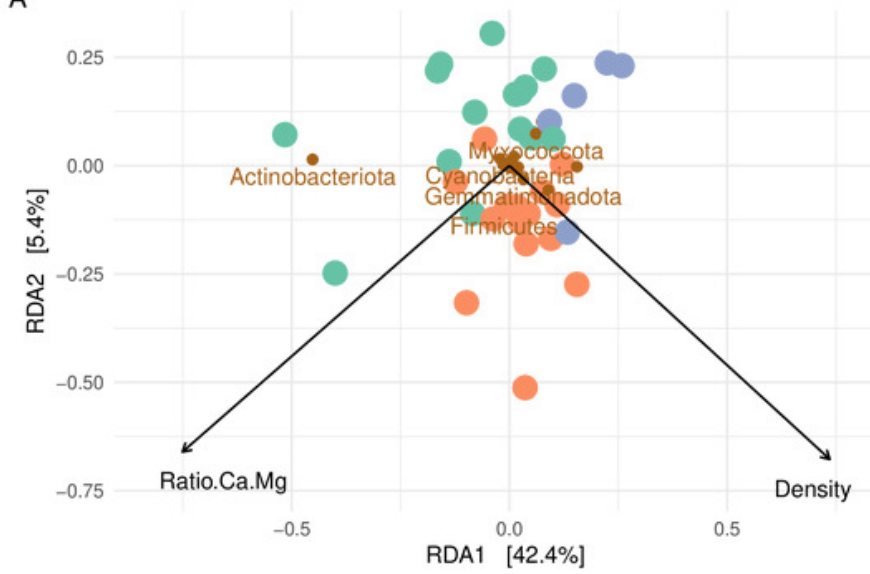

C

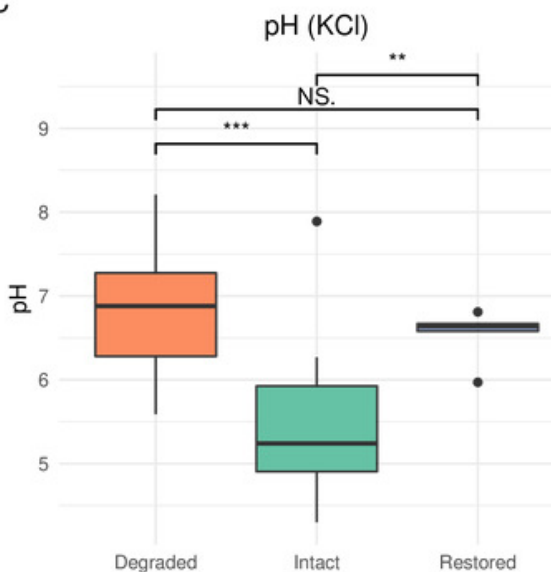

D
B
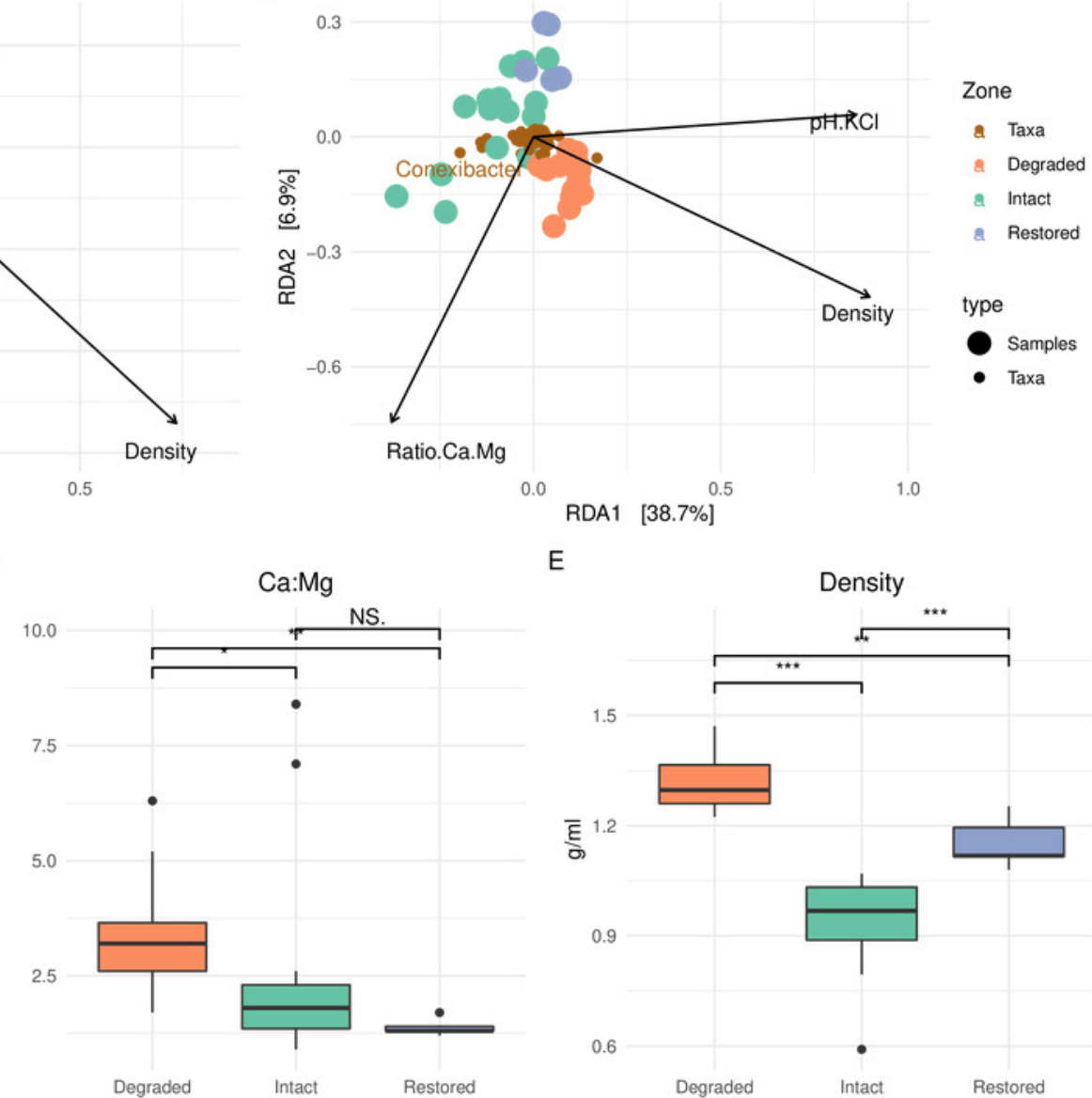

E

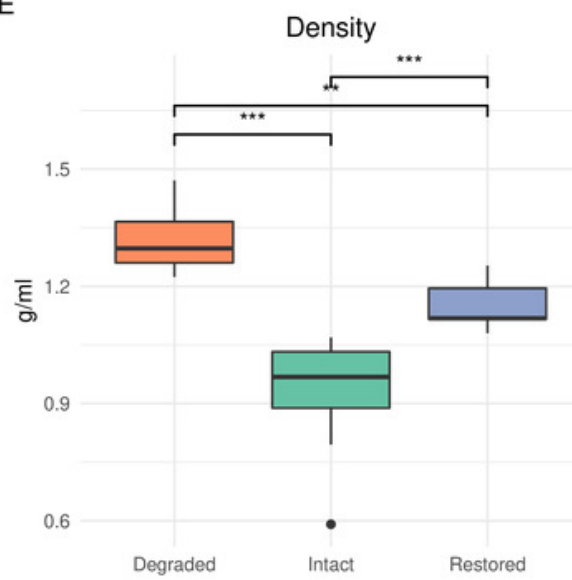




\section{Figure 6}

Co-occurrence network.

Co-occurrence network showing the 50 ASVs with the highest variance. Bold text indicates hub nodes and nodes of the same colour were clustered together. Blue edges indicate positive correlations and red edges indicate negative correlations between the connected nodes. The thicker the edge, the more similar the two nodes are to one another.
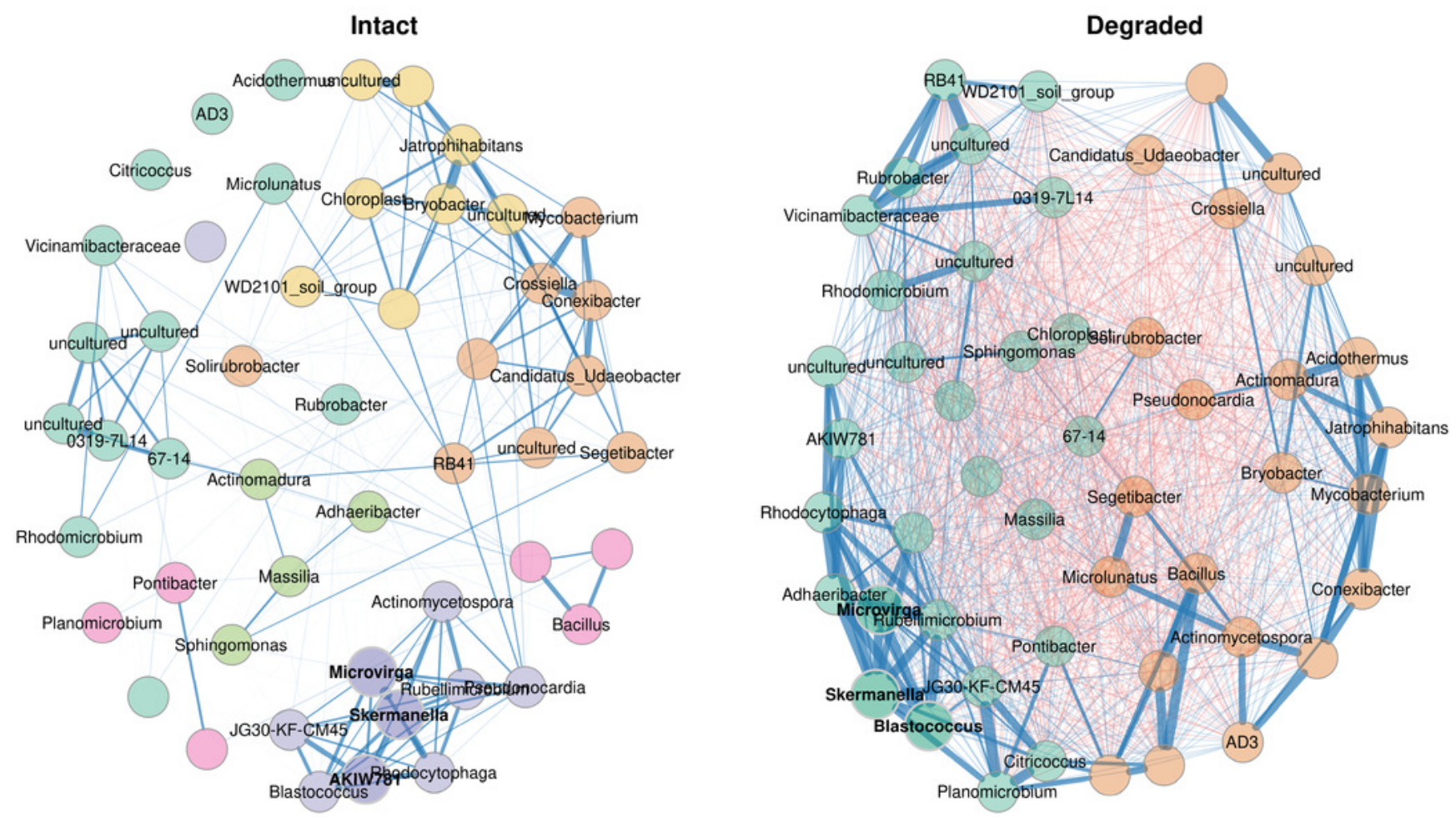